\title{
Developing Information System on Lunar Crescent Observations
}

\author{
T. Hidayat ${ }^{1}$, P. Mahasena ${ }^{1}$, B. Dermawan ${ }^{1}$, D. Herdiwijaya ${ }^{1}$, H. Setyanto ${ }^{1}$,

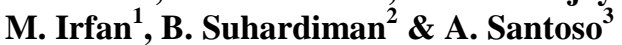 \\ ${ }^{1}$ Bosscha Observatory, Lembang 40391 \\ and Astronomy Research Division, FMIPA \\ ${ }^{2}$ Unit of Resources and Information \\ Institut Teknologi Bandung, Jl. Ganesha No. 10 Bandung 40132 \\ ${ }^{3}$ Department of Electrical Engineering \\ Institut Teknologi 10 November Surabaya \\ taufiq@as.itb.ac.id
}

\begin{abstract}
We present a progress report on the development of information system of lunar crescent astronomical observations which will be largely accessible for public domain. This consists of calculations of the Moon's ephemeris as well as systematic real-time lunar crescent observations. A well suited small telescope, equipped with a simple digital detector, is connected to a server to provide information on lunar crescent observations. The system has been used and worked well. The only constraint is poor weather condition. Network of small telescopes, installed at various locations in Indonesia, are currently planned to provide plethora of data. In the long term, this will be used to help to determine the astronomical visibility criteria of lunar crescent for Islamic calendar.
\end{abstract}

Keywords: lunar crescent observations; lunar information system; real-time observations.

\section{Introduction}

First lunar crescent viewing after conjunction is very important for Indonesian society, since it is mostly related to the determination of important dates in Islamic calendar. Although ephemeris of the moon are generally very accurate, many people still consider the importance to observe directly the appearance of lunar crescent. This affects considerably on the determination, for example, the beginning and the end of the Ramadan, which is very important to be decided equivocally.

Lunar crescent sighting is very difficult for some reasons. First, non-specialist observers usually do not know at what direction the object is located in the sky. Second, contrast between the object and the sky background is very low. Third, weather conditions influence considerably the observations, especially near the

Received December $26^{\text {th }}, 2009$, Revised February $2^{\text {nd }}, 2010$, Accepted for publication February $8^{\text {th }}, 2010$. 
horizon. Fourth, only a limited time is available to observe the lunar crescent before it sets below the horizon. Usually, the favorable situation is to observe the crescent just after the sunset. The time available is generally from a few minutes to less than an hour after the sunset. Therefore, successful observations require various favorable conditions.

In general, many layman volunteers three times a year conduct the naked-eye sighting of the thin lunar crescent shortly after a luni-solar conjunction, especially to determine the beginning of the fasting month, the fast-breaking, namely Eid-ul-Fitr, and the sacrifice-feast, called Eid-ul-Adha. The latter occurs on the tenth day of the last lunar month (Dhul-Hijja) corresponding to the period of Pilgrimage in Mecca. In fact, most observations reported by those volunteers are questionable from the astronomical point of view. They are mostly doubtful, not to mention erroneously. Usually, only a single person witnessed the thin crescent among thousands volunteers, located in various different positions, and the others were not able to watch. Therefore, the testimony is accepted without any verification. Worse, sometimes some volunteers announced to witness the crescent before the conjunction! This happens all those years in Indonesia.

Djamaluddin [1] has made a study of the reported sighting (between 1962 and 1997) in Indonesia to evaluate the validity of the resulting observations from the astronomical point of view. He concluded that most of the thin crescent reported sighting appeared to be confused by foreground bright objects, such as Venus. We could also mention a sociological study of the lunar crescent observations in Algeria reported by Guessoum \& Meziane [2]. The authors find that sightings between 1963 and 2000 are about $80 \%$ in error according to all the predictions criteria of visibility. An absolute impossibility was found to be as high as $17.4 \%$. According to these authors, the situation was even worse in the MiddleEast.

Therefore, the situation in Indonesia is likely the same, not to mention worse, since in this country, the beginning of the months may be different according to various Islamic organizations. The determination can be summarized as follows: (i) using only calculation by adopting a criterion, (ii) only sighting but supported with adequate prediction, (iii) only sighting with poor prediction.

Facing this situation, we propose to conduct a proper astronomical observation of the thin lunar crescent, and subsequently we transfer the data using largely accessible media such as internet and television broadcast. The main goal is mostly educative, and not intended to solve the problem immediately. The whole system is then able to provide an information system of the lunar crescent. Ideally, the observations must be conducted in many locations in the 
country to obtain more probable of good weather conditions. The observations must also be systematically performed for every new moon, and, thus, in the long term, the obtained data may help to propose a good criterion visibility.

\section{$2 \quad$ Astronomical Equipments}

For this purpose, we develop a simple and low-cost system of telescope, described in the self-explanatory Figure 1. The system consists of a small telescope, a simple digital detector, a universal adapter, a precise computerized mount, a laptop computer connected to the internet, and an adequate site with a good general western direction.

The telescope proposed for this system is a William Optics $66 \mathrm{~mm}$, f5.9, which is sufficient to provide a proportional lunar image in its field of view. It is not necessary to use a telescope with a large focal length since the contrast between the object and the sky background is generally very poor. The detector proposed is a also a simple digital camera, which has pre-assigned adaptable mode for various situation, e.g., a Powershot Canon $8 \mathrm{Mpix}$, and it is attached to the telescope using a universal adapter, tightened by any homemade bolt as shown in Figure 1.

An automatic mount is needed since the telescope must be pointed precisely to the object. A Sphinx SXW Vixen Mount is recommended, and the tracking can be calibrated using the Sun's position, provided with a mylar filter or ND5. A wide view camera could also be used to provide a panoramic view of the situation around the western direction. The general audience is thus also provided with a real-time information on local weather condition.

Finally, the data recorded by the camera must be transmitted to the laptop computer using, for example, a TV tuner or a video card capable of supporting a sufficient resolution, $640 \times 480$ points. The data are then transmitted to a remote server through internet connection. If the site does not provide any existing internet facility, one may use a wireless modem connected to a cellular communication provider. The electric power consumed by this system is low, and may be provided by a portable genset of $2 \mathrm{~kW}$.

This system is thus very simple and can be constructed and conducted in various regions in Indonesia, with relatively low cost. Therefore, it may be easily accessible by most grand public in Indonesia, especially those of specialized officers in the Department of Religion Affair in Indonesia. 

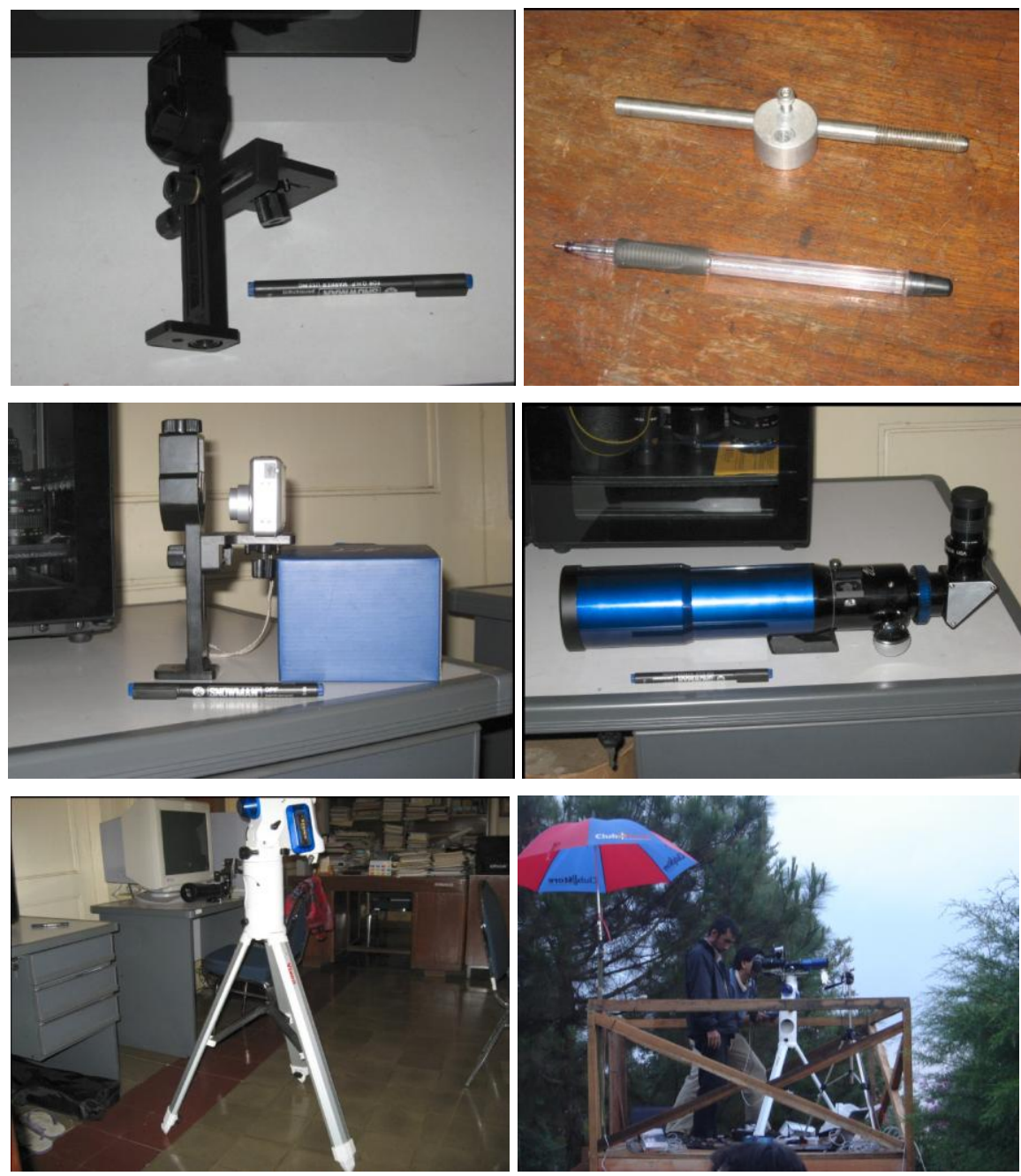

Figure 1 A simple and low-cost system of telescope, proposed for this purpose, is shown in the series of figures from top left to the bottom right. The system consists of a small telescope, a simple digital detector, a universal adapter, a precise computerized mount, a laptop computer connected to the internet, and an adequate site with a good general western direction.

\section{$3 \quad$ Broadcasting}

The case of developing information system is, however, not simple since this must be capable to accept many data from various locations of astronomical observations, and at the same time, the whole data should be able to be retrieved by any large audience. The first requirement is a high speed internet bandwidth. 


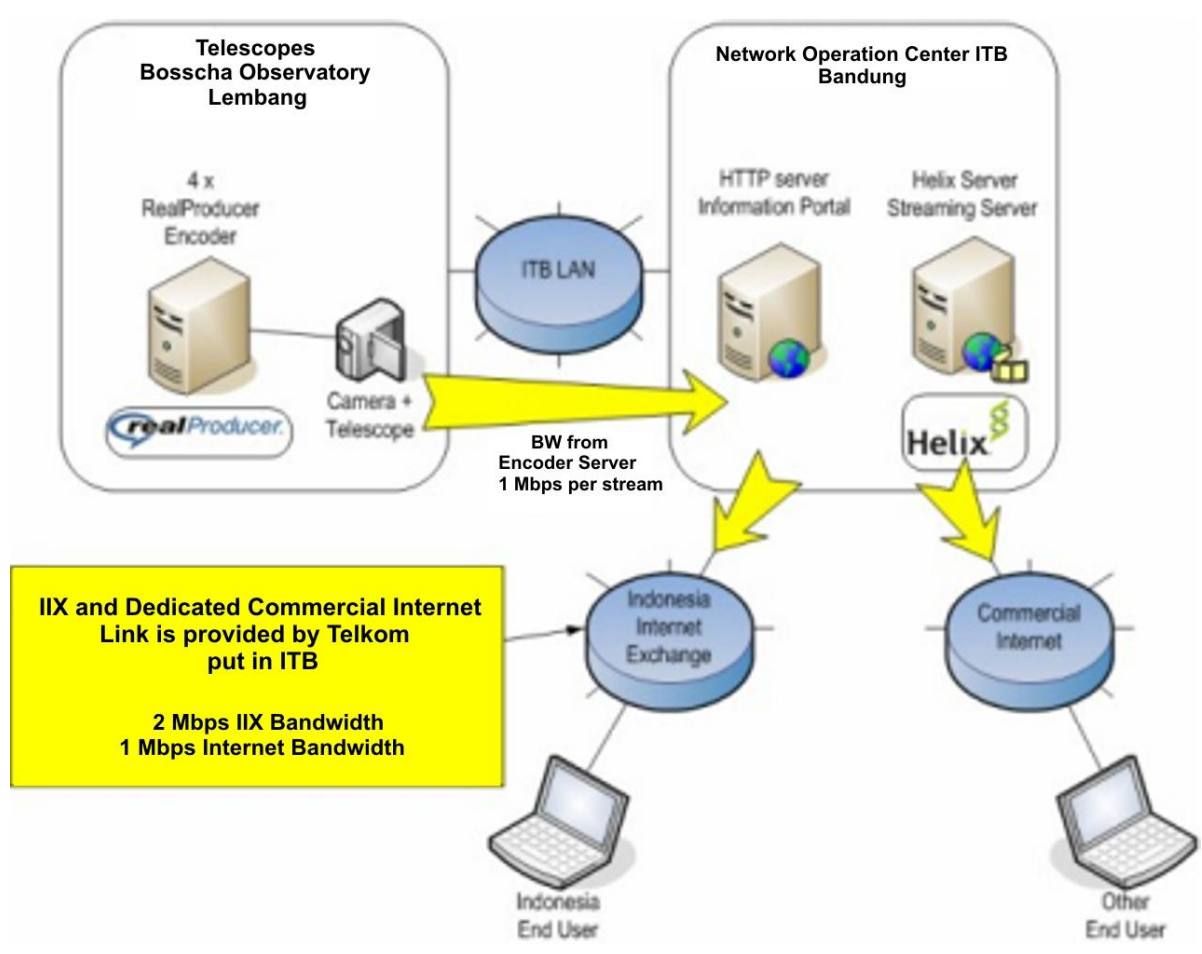

Figure 2 Schematic diagram of the information system developed to provide lunar crescent observations data to be largely accessible.

After considering many options, the information system developed for this purpose is described in Figure 2. Streaming servers are put at the Bosscha Observatory, and its number depends on the observing mode to be displayed. In our case, three servers are necessary for displaying: (i) simulation of the Moon's position, (ii) wide view observations, (iii) telescope observation. The selected streaming software is RealProducer since it can adjust the provided bandwidth in various channeling option from very low modem connection to a high speed LAN connection.

The streamed data are subsequently transmitted to a HelixServer, installed in USDI-ITB, and readily to receive data from various places of observations. The corresponding address of the HelixServer is rtsp://rbn.itb.ac.id/broadcast/hilal. Development and testing of the system were made in August to September 2007. Hence, any observer around the country may transmit his/her data after registering to the administrator. The data are then stored by the server for further data processing purposes. 
In order to allow accessible data easily, an interface of web server is then developed with various important information. Link to a wider access is channeled to IIX at $2 \mathrm{Mbps}$ and to the general internet at $1 \mathrm{Mbps}$. The latter is mostly intended to audience usually access ITB's servers. The channeling is necessary to prevent overload access on one server. This is made possible through collaboration with an ISP, namely PT Telkom, providing a high speed access to the ITB's servers.

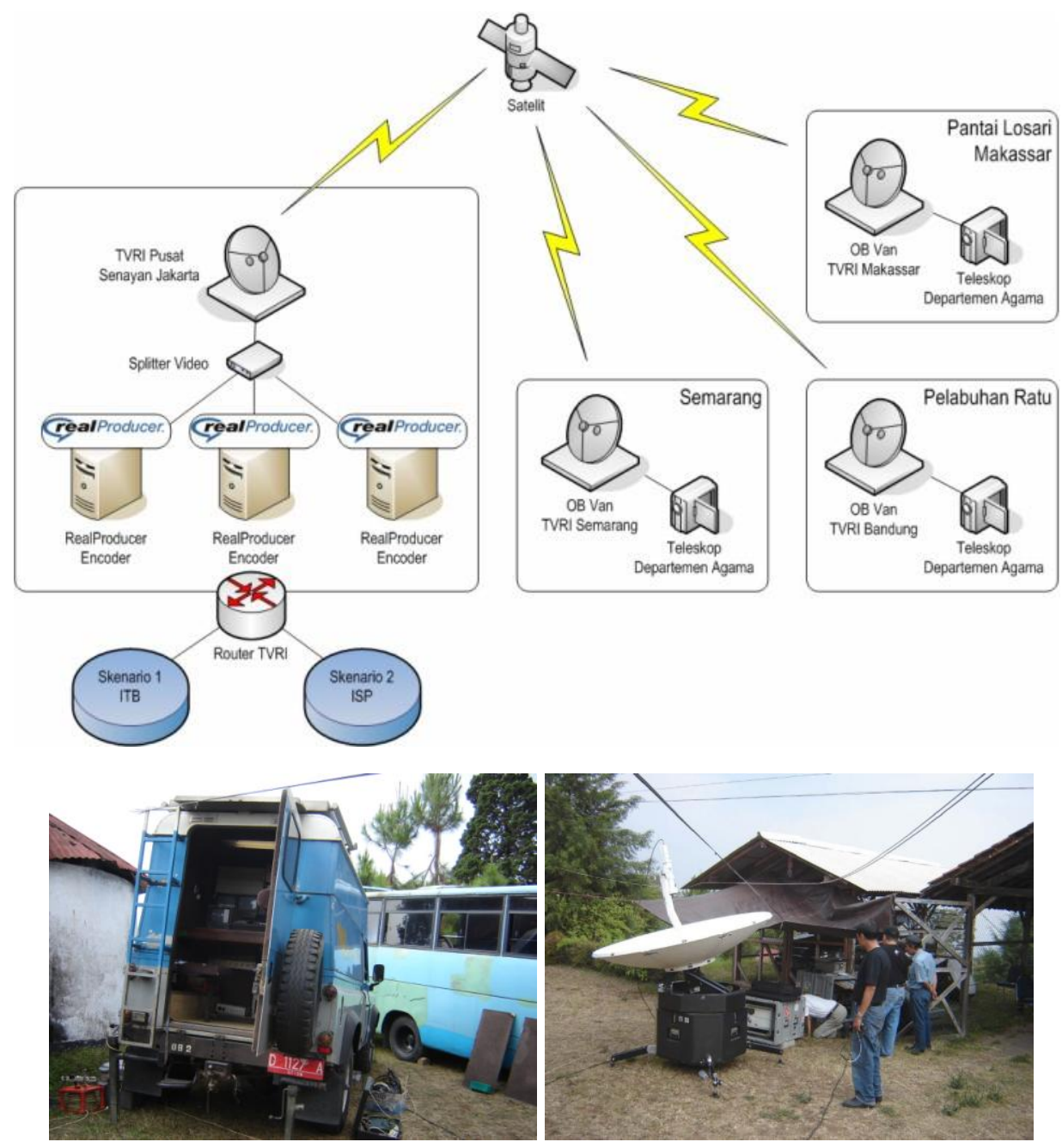

Figure 3 Schematic diagram to show the capability of the system to transmit the same information via a television broadcast (top panel). It was tested through cooperation with the TVRI in August and September 2007 at the Bosscha Observatory (bottom panel). 
In addition, this system must also support transmission for a wide media, such as national television. In this case, OB van of television can also be easily connected using a scheme described in Figure 3. In fact, in the long run all observations performed by 'official observers' from Department of Religion Affair must also be transmitted by this system. Testing for television broadcast has been successfully made through cooperation with TVRI in August and September 2007. This system is used since then with many improvements.

\section{$4 \quad$ Information Viewing}

It is worth mentioning that the information must be presented as easy as possible since it is mainly intended for lay men. This simple but accurate lunar information is also intended to help the government to decide the important religious days, such as the beginning and the end of Ramadan. The whole information is finally accessible via a web server, with URL address: http://bosscha.itb.ac.id/hilal as shown in Figure 4. First, basic astronomical information on lunar crescent ephemeris computation and observations are presented. Subsequently, information on local weather condition is displayed using the existing weather forecast calculation made by the meteorological group of ITB (http://weather.geoph.itb.ac.id). This should help the audience to be aware of the importance of weather influence on the observations.

Second, simulation of the Moon's position is also displayed for every region in which the observations are conducted. This yields the position, time of sunset and moonset, and how its motions to the corresponding horizons. Ones may immediately compare to the naked-eye sighting they make in their own positions.

Third, the real-time observations can be viewed in subsequent pages and one can check any time the results from every region of observations. Depending on the instrument setups, panoramic and telescopic viewing may be provided. Meteorological conditions are updated in each observing window by the accompanying running text. If a television channel participates for a broadcast, a snapshot of each region window can be shown, accompanied by interactive talks both from the channel studio and the observing sites. This system thus constitutes a wide information system on lunar crescent observations which are easily accessible for large public. Everyone, therefore, can witness whether the crescent is visible or not. After 3 years of operation, this information system gets more than one million hits which prove its important roles for Indonesian society. It is now relayed using a new URL at http://hilal.depkominfo.go.id to provide wider and easier access, especially to give real-time information during the government meeting to decide the beginning and the end of Ramadan. 

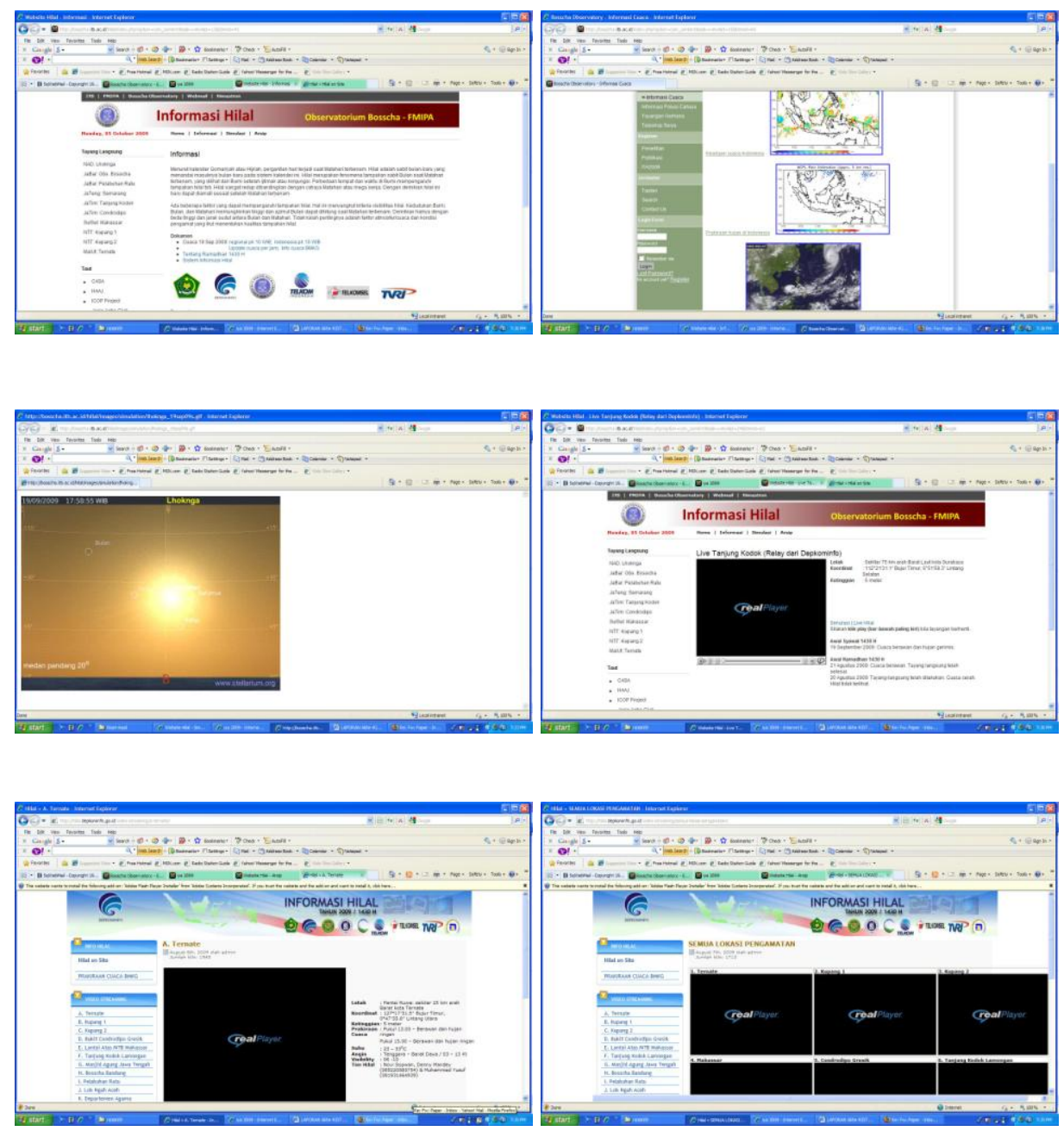

Figure 4 Web pages to display the information of lunar crescent observations. Simulation of the Moon and the Sun motions are shown at the middle panel, and the corresponding real-time observations are shown at the bottom panel. Various other informations may also be found at the URL address: http://bosscha.itb.ac.id/hilal and http://hilal.depkominfo.go.id (bottom panel). 

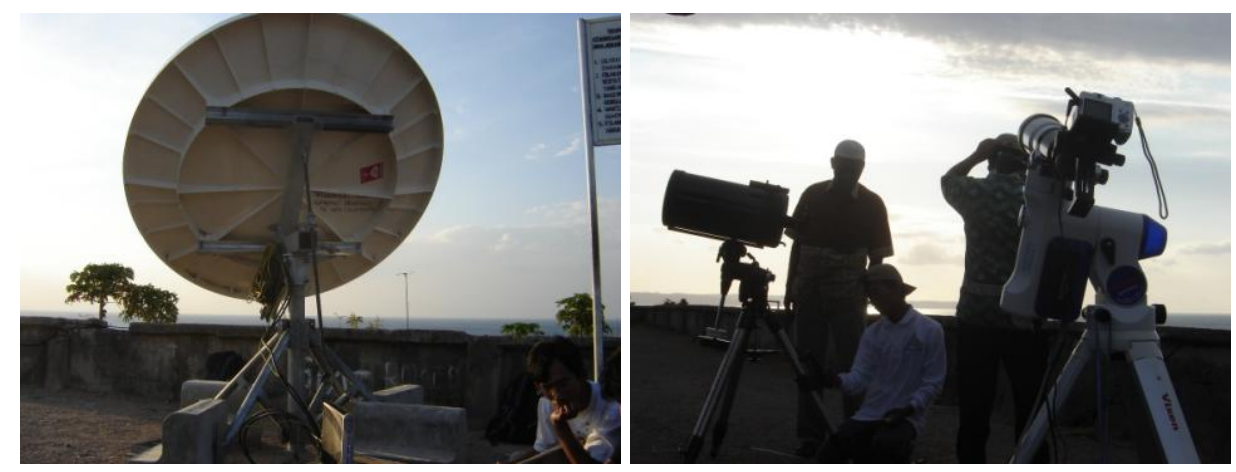

Figure 5 Lunar crescent observations are made in some remote areas in Indonesia. The pictures above show observations conducted in Kupang. Link to satellite was provided by Telkomsel.

\section{$5 \quad$ Observations}

This system was performed consecutively starting in August 2007 until present. The first observing testing was made on $13^{\text {th }}$ and $14^{\text {th }}$ August 2007 at the Bosscha Observatory, Lembang, West Java, and the data streaming was successfully displayed at the office of Ministry of Communication and Informatics. Weather condition was not quite good because clouds covered mostly western horizon. The luni-solar conjunction occurred on $13^{\text {th }}$ August 2007 , at 6.03 local time, sunset at 17.50 , followed by moonset at 18.12 . the moon altitude at sunset was $5^{\circ} 9^{\prime}$ with disk illumination only $0.27 \%$ and elongation of $5^{\circ} 55^{\prime}$. The moon age was $11 \mathrm{~h} 48 \mathrm{~m}$, and the crescent was not successfully observed. The following day, the weather was better but the cloud still present above the horizon. Finally, the crescent was successfully recorded, shown in Figure 6 (left), at an altitude about $12^{\circ}$ above the horizon with illumination of $2.34 \%$. Observations, transmitted using both internet and television, were subsequently conducted on $28^{\text {th }}$ August 2007 on the occasion of total lunar eclipse passing Indonesia.

With this successful testing, we subsequently sent a 'lunar expedition' to various regions in Indonesia. On $12^{\text {th }}$ and $13^{\text {th }}$ September 2007, observations were made at Losari Beach, (Makassar, South Sulawesi), Bukit Condrodipo (Gresik, East Java), the Tower of Mesjid Agung (Semarang, Central Java), the Bosscha Observatory (Lembang, West Java), and the Tower of Mesjid Baiturrahman (Banda Aceh, Aceh) to try to catch the crescent of the Ramadan. The selected region represents a province of Indonesia, and the number should be increasing in the future. 

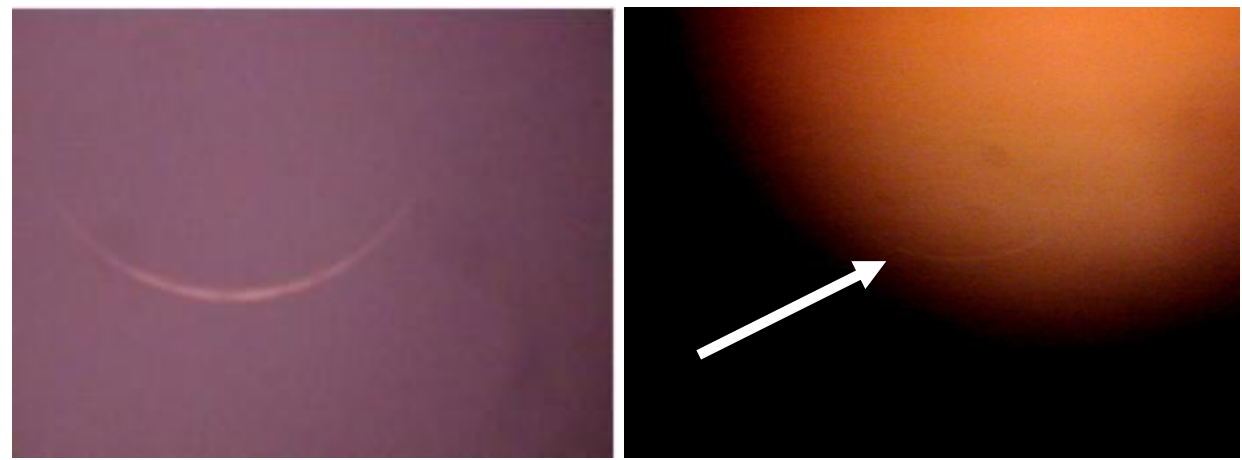

Figure 6 A lunar crescent observed on $14^{\text {th }}$ August 2007 (left) and on $9^{\text {th }}$ January 2008 (right) at the Bosscha Observatory. The disk illumination was $2.34 \%$ and $1.04 \%$, respectively. The latter is shown by the arrow, and was impossible to be seen through naked-eye observations.

Similar observations were also made on $12^{\text {th }}$ and $13^{\text {th }}$ October 2007 at 6 different locations: Soe (Kupang, East Nusa Tenggara), Losari Beach, (Makassar, South Sulawesi), Tanjung Kodok Beach (Lamongan, East Java), the Tower of Mesjid Agung (Semarang, Central Java), the Bosscha Observatory (Lembang, West Java), and the Tower of Mesjid Baiturrahman (Banda Aceh, Aceh) to try to catch the crescent of the fast-breaking. However, none of these observations successfully recorded the crescent merely due to bad weather conditions.

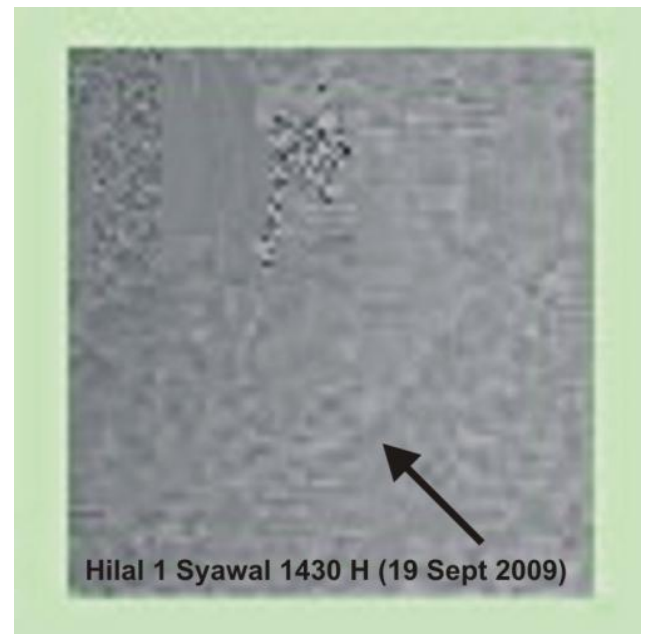

Figure 7 Example of a very thin crescent shown after an image processing to enhance the detection. 


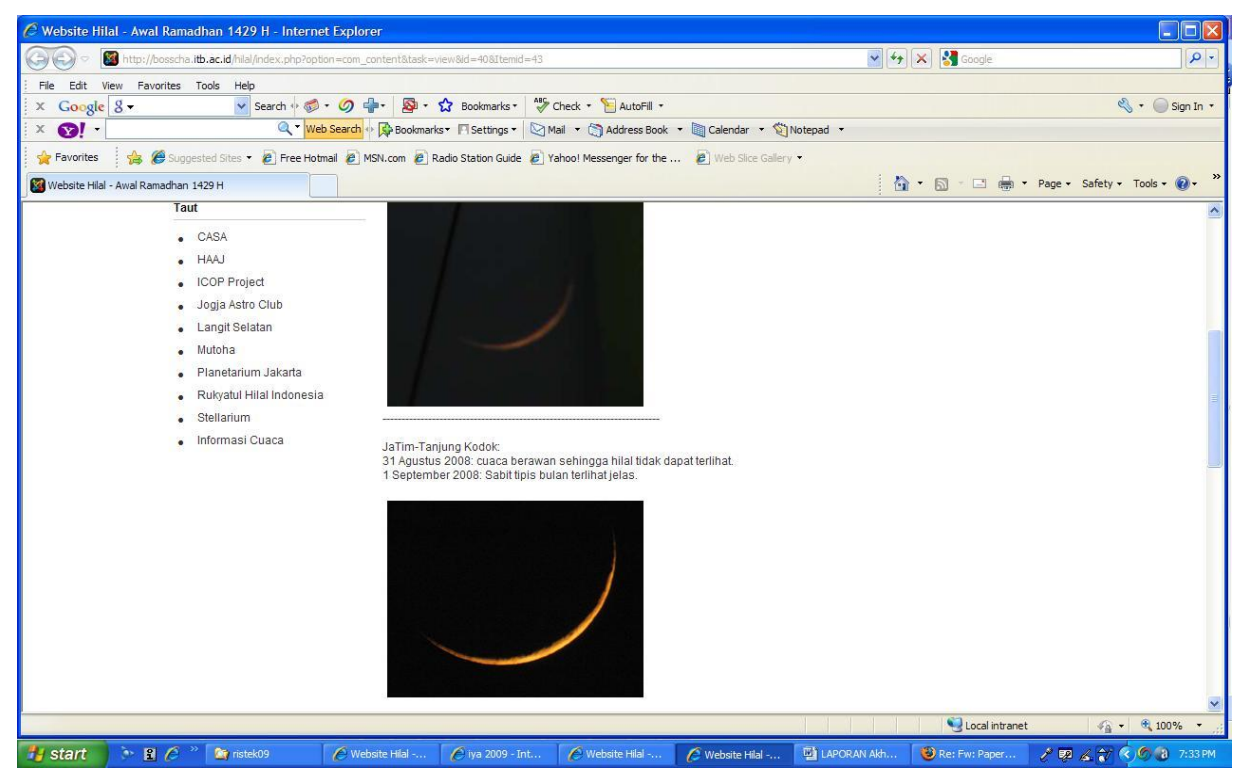

Figure 8 Archival of data is provided in the website, both in still and video images for further analysis.

Subsequent attempts at the Bosscha Observatory were made consecutively from November 2007 until November 2009, for every new moon, during the rainy season. Most observations were also unsuccessful due to bad weather conditions. A successful observation was made on $9^{\text {th }}$ January 2008 , shown in Figure 6 (right). The image was successfully recorded where a small hole in a cloudy condition still permitted a clear lunar crescent image. The illumination was $1.04 \%$, corresponding to the moon age of $23^{\mathrm{h}} 34^{\mathrm{m}}$. The contrast in the picture was enhanced by a factor of $70 \%$. We note that this image could not be perceived through naked-eye observations and it demonstrates the goodness of the pointing of the telescope, despite this was referred to a single point, i.e., to the Sun, and the tracking to the Moon followed accordingly. Hence, the only constraint found in this system is poor weather conditions. Figure 7 shows a result of observations conducted on 19 September 2009 in Semarang after an image processing. It is another example of a very thin crescent of $0.77 \%$ illumination, moon age $16^{\mathrm{h}} 01^{\mathrm{m}}$ and altitude $+06^{\circ} 23^{\prime} 33^{\prime \prime}$ which is very difficult to detect.

Table 1 summarizes the observations made for 17 periods of observations at the Bosscha Observatory. This result is encouraging since it is so far in agreement with the results presented in [3], i.e., no observations successfully recorded lunar crescent at the age less than 13 hours. With the successful implementation of this system, observations during 2009 have covered 10 regions in Indonesia: 
1 in Ternate, 2 in NTT, 1 in South Sulawesi, 2 in East Java, 1 in Central Java, 2 in West Java, and 1 in Aceh. A significant growth of this network is expected in the near future, involving more skillful people in observational astronomy. Archival of the data (Figure 8), accessible in public domain, will constitute a database to develop a scientific criterion of the first crescent visibility.

Table 1 Summary of the first lunar crescent Observations at the Bosscha Observatory (longitude $107^{\circ} 36^{\prime} 55.2^{\prime \prime} \mathrm{E}$, latitude $6^{\circ} 49^{\prime} 29.3^{\prime \prime} \mathrm{S}$ ).

\begin{tabular}{|c|c|c|c|c|c|}
\hline No & Observations & $\begin{array}{c}\text { Moon } \\
\text { Altitude }\end{array}$ & Moon Age & $\begin{array}{c}\text { Illumination } \\
(\%)\end{array}$ & Remark \\
\hline \multirow[t]{2}{*}{1} & 13 August 2007 & $+05^{\circ} 09^{\prime} 06^{\prime \prime}$ & $11^{\mathrm{h}} 48^{\mathrm{m}}$ & $0.27 \%$ & I \\
\hline & 14 August 2007 & $+16^{\circ} 20^{\prime} 42^{\prime \prime}$ & $35^{\mathrm{h}} 48^{\mathrm{m}}$ & $2.34 \%$ & $\mathrm{~S}$ \\
\hline \multirow[t]{2}{*}{2} & 11 September 2007 & $-01^{\circ} 33^{\prime} 02^{\prime \prime}$ & $-01^{\mathrm{h}} 57^{\mathrm{m}}$ & $0.01 \%$ & $\mathrm{I}^{+}$ \\
\hline & 12 September 2007 & $+08^{\circ} 33^{\prime} 02^{\prime \prime}$ & $22^{\mathrm{h}} 03^{\mathrm{m}}$ & $0.84 \%$ & $\mathrm{~F}$ \\
\hline \multirow[t]{2}{*}{3} & 11 October 2007 & $+00^{\circ} 46^{\prime} 18^{\prime \prime}$ & $05^{\mathrm{h}} 42^{\mathrm{m}}$ & $0.15 \%$ & $\mathrm{I}^{+}$ \\
\hline & 12 October 2007 & $+11^{\circ} 49^{\prime} 20^{\prime \prime}$ & $29^{\mathrm{h}} 42^{\mathrm{m}}$ & $1.52 \%$ & $\mathrm{~F}$ \\
\hline \multirow[t]{2}{*}{4} & 10 November 2007 & $+03^{\circ} 39^{\prime} 45^{\prime \prime}$ & $11^{\mathrm{h}} 42^{\mathrm{m}}$ & $0.04 \%$ & I \\
\hline & 11 November 2007 & $+14^{\circ} 23^{\prime} 12^{\prime \prime}$ & $35^{\mathrm{h}} 42^{\mathrm{m}}$ & $2.18 \%$ & $\mathrm{~F}$ \\
\hline \multirow[t]{2}{*}{5} & 10 December 2007 & $+07^{\circ} 22^{\prime} 39^{\prime \prime}$ & $17^{\mathrm{h}} 17^{\mathrm{m}}$ & $0.64 \%$ & $?$ \\
\hline & 11 December 2007 & $+18^{\circ} 34^{\prime} 02^{\prime \prime}$ & $41^{\mathrm{h}} 17^{\mathrm{m}}$ & $2.91 \%$ & $\mathrm{~F}$ \\
\hline 6 & 9 January 2008 & $+10^{\circ} 51^{\prime} 33^{\prime \prime}$ & $23^{\mathrm{h}} 34^{\mathrm{m}}$ & $1.04 \%$ & $S$ \\
\hline \multirow[t]{2}{*}{7} & 7 February 2008 & $+02^{\circ} 54^{\prime} 06^{\prime \prime}$ & $07^{\mathrm{h}} 30^{\mathrm{m}}$ & $0.11 \%$ & I \\
\hline & 8 February 2008 & $+13^{\circ} 33^{\prime} 21^{\prime \prime}$ & $31^{\mathrm{h}} 30^{\mathrm{m}}$ & $2.02 \%$ & $\mathrm{~F}$ \\
\hline 8 & 8 March 2008 & $+06^{\circ} 20^{\prime} 17^{\prime \prime}$ & $17^{\mathrm{h}} 51^{\mathrm{m}}$ & $0.78 \%$ & $?$ \\
\hline 9 & 7 April 2008 & $+12^{\circ} 22^{\prime} 27^{\prime \prime}$ & $30^{\mathrm{h}} 56^{\mathrm{m}}$ & $2.61 \%$ & $\mathrm{~F}$ \\
\hline 10 & 2 August 2008 & $+12^{\circ} 34^{\prime} 11^{\prime \prime}$ & $24^{\mathrm{h}} 38^{\mathrm{m}}$ & $1.41 \%$ & S \\
\hline \multirow[t]{2}{*}{11} & 31 August 2008 & $+6^{\circ} 51^{\prime} 37^{\prime \prime}$ & $14^{\mathrm{h}} 51^{\mathrm{m}}$ & $0.51 \%$ & $\mathrm{~F}$ \\
\hline & 1 September 2008 & $+17^{\circ} 37^{\prime} 09^{\prime \prime}$ & $38^{\mathrm{h}} 51^{\mathrm{m}}$ & $3.15 \%$ & S \\
\hline \multirow[t]{2}{*}{12} & 29 September 2008 & $-00^{\circ} 40^{\prime} 56^{\prime \prime}$ & $2^{\mathrm{h}} 32^{\mathrm{m}}$ & $0.13 \%$ & $\mathrm{I}^{+}$ \\
\hline & 30 September 2008 & $+10^{\circ} 24^{\prime} 35^{\prime \prime}$ & $26^{\mathrm{h}} 32^{\mathrm{m}}$ & $1.46 \%$ & $\mathrm{~S}$ \\
\hline 13 & 25 May 2009 & $+10^{\circ} 29^{\prime} 11^{\prime \prime}$ & $22^{\mathrm{h}} 28^{\mathrm{m}}$ & $1.39 \%$ & $\mathrm{~F}$ \\
\hline \multirow[t]{2}{*}{14} & 22 July 2009 & $+04^{\circ} 02^{\prime} 09^{\prime \prime}$ & $08^{\mathrm{h}} 15^{\mathrm{m}}$ & $0.18 \%$ & I \\
\hline & 23 July 2009 & $+17^{\circ} 56^{\prime} 21^{\prime \prime}$ & $32^{\mathrm{h}} 15^{\mathrm{m}}$ & $2.76 \%$ & $\mathrm{~S}$ \\
\hline \multirow[t]{2}{*}{15} & 20 August 2009 & $-00^{\circ} 53^{\prime} 07^{\prime \prime}$ & $00^{\mathrm{h}} 49^{\mathrm{m}}$ & $0.05 \%$ & $\mathrm{I}^{+}$ \\
\hline & 21 August 2009 & $+12^{\circ} 16^{\prime} 30^{\prime \prime}$ & $24^{\mathrm{h}} 48^{\mathrm{m}}$ & $1.66 \%$ & $\mathrm{~F}$ \\
\hline 16 & 19 September 2009 & $+06^{\circ} 23^{\prime} 33^{\prime \prime}$ & $16^{\mathrm{h}} 01^{\mathrm{m}}$ & $0.77 \%$ & $\mathrm{~F}^{*}$ \\
\hline 17 & 17 November 2009 & $+06^{\circ} 22^{\prime} 19^{\prime \prime}$ & $15^{\mathrm{h}} 34^{\mathrm{m}}$ & $0.56 \%$ & $\mathrm{~F}$ \\
\hline
\end{tabular}

Note: $\mathrm{I}=$ impossible to be observed, $\mathrm{S}=$ successful, $\mathrm{F}=$ fail, ? = difficult to determine

*) Successfully detected in Semarang (see text); ${ }^{+}$) Mandatory observations 


\section{Concluding Remark and Further Work}

From the results described in the above section, weather condition is very penalizing for thin lunar crescent observations. However, we strongly believe that a simple and low-cost astronomical equipment set may be used to properly observe the object. This system is thus appropriate to introduce observational astronomy for public at large. In the future, a network of small telescopes should be developed throughout the country to which they are interconnected. An observatory at suitable dry condition must also be constructed to perform systematic observations.

We note that a reliable internet connection is a primary requirement to support the system. Servers for the information system must also be maintained at higher performance, and it could be open for a wider data upload and download to the community (amateur astronomy, for example).

Again, this system may not help to resolve immediately the problem of Islamic lunar calendar. But in the long term, the database collected by the system may support for research on data processing techniques. Accordingly, research on the crescent visibility criteria can also be conducted (for more details, see for example, references [4-7]). In addition, a more sophisticated system is now undertaken at the Bosscha Observatory.

\section{Acknowledgement}

This work is supported by Ministry of Communication and Informatics and Ministry of Religion Affair, Republic of Indonesia, TVRI, PT Telekomunikasi Indonesia, and PT Telkomsel, to whom we are sincerely indebted. We also wish to express our special thanks to Suhono H. Supangkat, Hadwi Soendjojo, Wahyu Hidayat, and Affan Bassalamah for their significant help during the implementation of this work.

\section{References}

[1] Djamaluddin, T., Re-evaluation of Hilaal Visibility in Indonesia (http://www.icoproject.org/pdf/djamaluddin_2001_in.pdf); and Visibilitas Hilal di Indonesia, Warta LAPAN, 2(4), 137-136, 2000.

[2] Guessoum, N. \& Meziane, K., Visibility of the thin lunar crescent: The sociology of an astronomical problem (A case study), Journal of Astron. History and Heritage, 4, 1-14, 2001.

[3] Schaefer, B. E., Ahmad, I. A. \& Doggett, L. R., Records for Young Moon Sightings, Quart. Journal of the Royal Astron. Society, 34, 53-56, 1993. 
[4] Bruin, F., The first visibility of the lunar crescent, Vistas in Astronomy, 21, 331-358, 1977.

[5] Schaefer, B.E., Length of the Lunar Crescent, Quart. Journal of the Royal Astron. Society, 32, 265-277, 1991.

[6] Doggett, L.,E. \& Schaefer, B.E., Lunar Crescent Visibility, Icarus, 107, 388-403, 1994.

[7] B.E. Schaefer, Lunar Crescent Visibility, Quart. Journal of the Royal Astron. Society, 37, 759-768, 1991. 